\title{
DIREÇÃO DE TRANSPORTE SEDIMENTAR NA DESEMBOCADURA DO RIO ITANHÉM, EXTREMO SUL DA BAHIA. APLICAÇÃO DO MÉTODO DE GAO \& COLLINS E KRIGAGEM VETORIAL
}

\author{
Luciano V. Ribeiro', Henri Dupont ${ }^{1}$, Emerson C. Bodevan², Paulo S. Lúcio² \\ RESUMO
}

\begin{abstract}
A zona costeira do extremo sul da Bahia tem sido relacionada a diversos impactos ambientais incluindo o desmatamento da Floresta Atlântica, a erosão costeira e o assoreamento de desembocaduras de rios. Com o intuito de entender a dinâmica do transporte de sedimentos na desembocadura do rio Itanhém foram coletadas 185 amostras de sedimentos de fundo distribuídas na área pesquisada. A metodologia adotada compara as variações espaciais dos três parâmetros estatísticos média, desvio padrão (coeficiente de seleção) e assimetria entre amostras vizinhas. Associações destas variações de parâmetros podem indicar a direção do transporte de sedimentos. A associação mais usual determina que o sedimento torna-se mais fino, melhor selecionado e mais negativamente assimétrico na direção do transporte. De um total de oito possibilidades de associação da variação dos três parâmetros as três outras que mostram, também, uma melhora da seleção são, também, relacionadas ao transporte de sedimentos.

A desembocadura do rio Itanhém recebe sedimentos tanto da deriva litorânea quanto da drenagem continental. Estes sedimentos tendem a acumular-se em bancos de areia, que formam um delta de maré vazante. Sedimentos são, também, transportados para montante do estuário através das correntes de maré enchente e são depositados na barra de pontal com acreção sedimentar lateral às margens do estuário.
\end{abstract}

\section{INTRODUÇÃO}

O transporte de sedimentos ocorre de várias maneiras na natureza, tanto em ambiente subaéreo quanto em ambiente subaquoso. Para que uma partícula repousando em uma superfície entre em movimento é necessária a atuação de forças que superem ambas as forças de gravidade e de atrito atuando nesta partícula. Fluidos em movimento, como o ar (ventos) ou a água (correntes fluviais, lacustres ou marinhas), atuam na interface sedimento-ar ou sedimento-água, provocando o transporte sedimentar nos diversos ambientes naturais. De outra forma, o equilíbrio de repouso pode ser rompido pela própria força da gravidade deslocando grandes massas de material em deslizamentos de encostas.

As direções do transporte de sedimentos usualmente são estudadas através das estruturas sedimentares direcionais entre as quais certas formas de leito e laminações oblíquas possuem relação direta com as direções e os tipos de fluxo atuantes. Outra maneira bastante usual para inferir sobre as direções do transporte de sedimentos é o uso de traçadores radioativos ou fluorescentes que permitem seguir as partículas em movimento. Neste estudo, entretanto, será utilizada uma metodologia diferente de analisar o transporte de sedimentos. Esta recorre a uma coleta de sedimento de fundo espacialmente distribuída na área de pesquisa. A granulometria do sedimento amostrado, mais precisamente três parâmetros granulométricos (média, seleção e assimetria) são utilizados para identificar a tendência do transporte de sedimento. Essa metodologia de estudo foi idealizada no início dos anos 80 por McLaren (1981) e McLaren \& Bowles (1985), e vem sendo sucessivamente desenvolvida por outros autores (Gao \& Collins, 1991; 1992; Le Roux, 1994a e b; Asselman, 1996). Este método de analisar o transporte de sedimentos já foi aplicado com sucesso em diversos locais do mundo, porém, no Brasil, segundo nosso conhecimento, é a primeira vez que se utiliza esta ferramenta (Dupont et al. 2000).

Este artigo apresenta os resultados obtidos para o transporte de sedimentos na desembocadura do rio Itanhém através dos métodos de Gao \& Collins e de Krigagem Vetorial. A aplicação do Método de McLaren e do Método de Asselman, assim como a análise do transporte de sedimentos na zona litorânea de Alcobaça estão disponíveis em Ribeiro, (2000).

\section{ÁREA DE ESTUDO: A DESEMBOCADURA DO RIO ITANHÉM}

O rio Itanhém deságua no mar no município de Alcobaça, no extremo sul da Bahia (Fig. 1, Foto 1). Neste local, forma-se um estuário constituído principalmente por sedimentos lamosos formando manguesais. Próximo ao encontro com o mar, os sedimentos do estuário são predominantemente arenosos. A desembocadura do rio Itanhém apresenta uma restinga em crescimento na direção sul, que separa o estuário do rio Itanhém do delta de maré, formado em mar aberto. A restinga impede o rio Itanhém de desaguar diretamente no mar, forçando a mudança de sua direção para sul. Esta curvatura do rio imposta pela restinga causa o crescimento de uma barra de pontal em sua parte convexa. Grande parte desta barra de pontal fica exposta durante a maré baixa (Foto 2). A margem oposta à barra de pontal apresenta feições erosivas exibindo barrancos onde o rio retrabalha os sedimentos. $\mathrm{O}$ canal do rio Itanhém nesta parte do estuário possui em média 2 metros de profundidade, atingindo em alguns locais profundidades superiores a 3 metros. Outra feição geomorfológica importante nessa parte do estuário é a formação de pequenas planícies de maré lamosas na restinga, que são inundadas apenas durante a maré cheia. O rio Itanhém, quando deságua no mar, forma um delta de maré vazante. Essas acumulações de sedimentos são os corpos de areia mais comuns associados com 


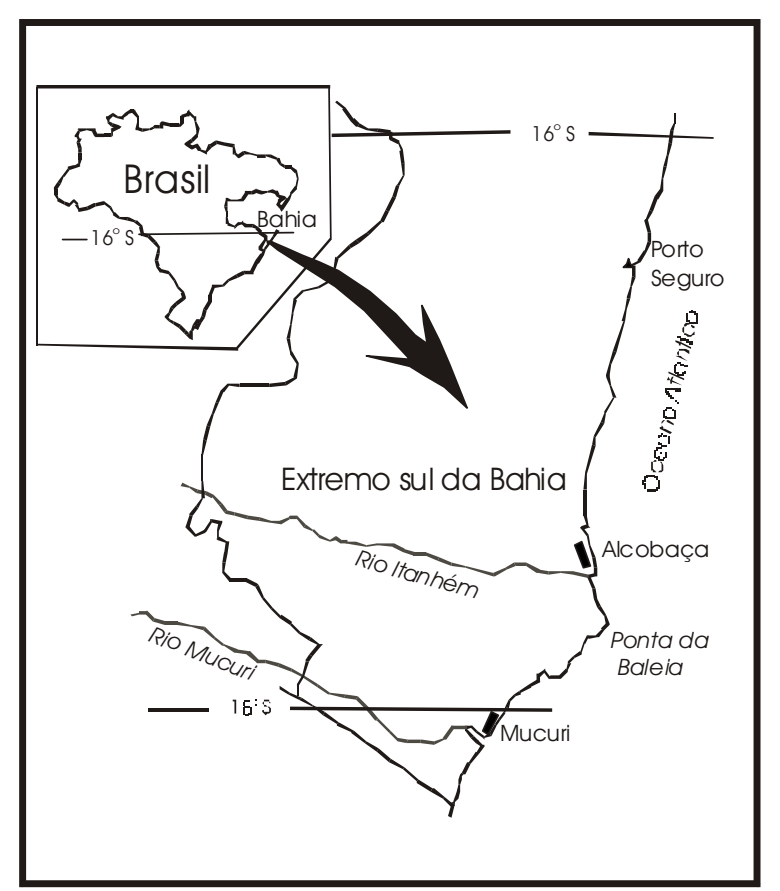

Figura 1: Mapa de localização do extremo sul da Bahia.

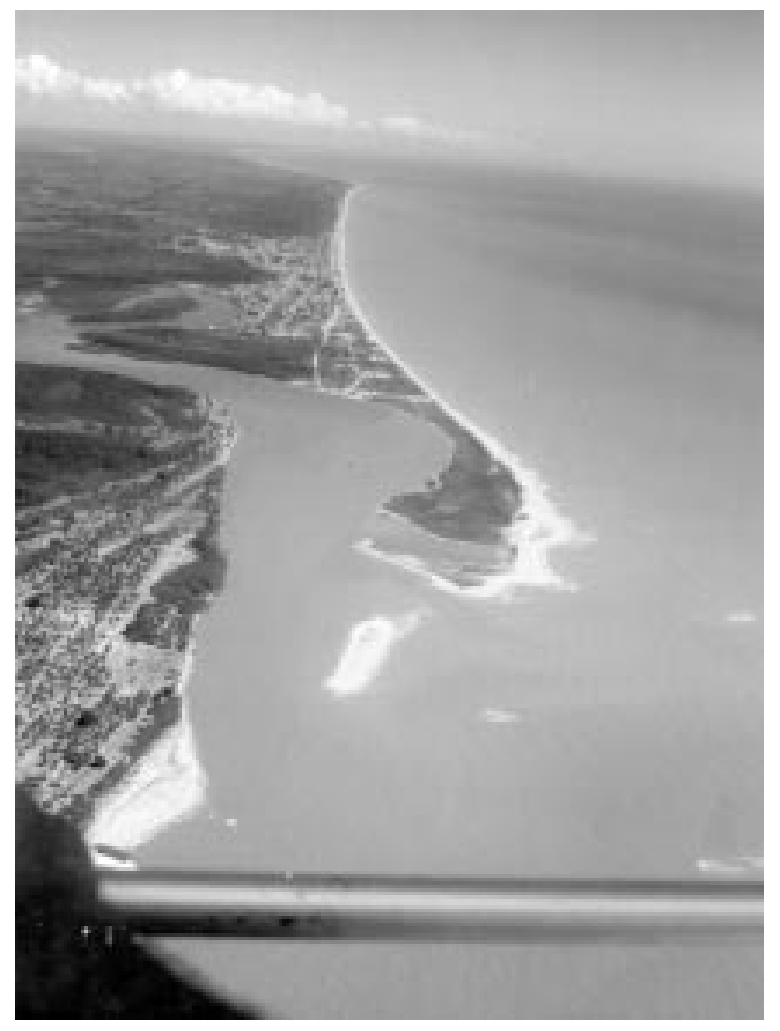

Foto 1: Vista aérea de Alcobaça e do estuário do rio Itanhém (vista para norte, na maré alta)

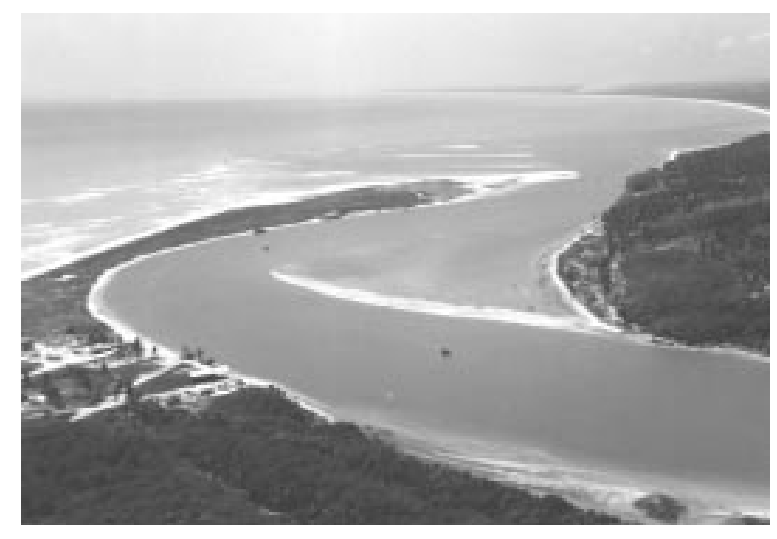

Foto 2: Vista aérea do estuário do rio Itanhém, da barra de pontal, da restinga em crescimento e do delta de maré vazante (vista para sul, na maré baixa).

estuários (Davis, 1983), que ocorrem em forma de leques nas bocas estreitas de estuários ou em entradas que servem o estuário. Os deltas de maré são melhor desenvolvidos em estuários de mesomaré (maré entre 2 e 4 metros), mas também são comuns em alguns estuários de micromaré (maré menor que 2 metros). Em Alcobaça, as marés são semi-diurnas e atingem, durante o período de sizígia, 2 metros de amplitude máxima. Estes corpos são chamados de deltas devido a sua forma geral e porque seu modo de formação é similar aos deltas dominados por rios. Um volume grande de sedimentos acumula devido à repentina perda de competência das correntes de marés. Cada estuário pode conter um delta de maré enchente, gerado por correntes de inundação e depositado no interior do estuário, e um delta de maré vazante que é gerado pelo refluxo da maré e depositado em mar aberto. $\mathrm{O}$ delta de maré vazante do rio Itanhém apresenta uma batimetria extremamente rasa, expondo diversos bancos de areia durante a maré baixa (Fig. 2). Neste período, a profundidade não ultrapassa 1 metro em toda a extensão estudada. Os bancos de areia estão orientados preferencialmente na direção leste-oeste alongados perpendicularmente à linha de costa. Esta configuração dos bancos de areia sugere o modelamento pela ação das correntes de maré. Entretanto, a forma de meia lua ou o arqueamento de alguns bancos indica o retrabalhamento por ondas. O canal principal do delta é a continuação do canal fluvial do rio Itanhém em mar aberto e, lateralmente a este, entre os bancos de areia, ocorrem pequenos canais distributários, geralmente paralelos ou perpendiculares à costa.

Fato importante a ser ressaltado é que se tem verificado nas últimas décadas uma intensificação da sedimentação no delta promovendo o assoreamento da desembocadura do rio Itanhém. Este assoreamento é também identificado em muitos outros locais do litoral sul da Bahia, tendo como causa principal o desmatamento progressivo da 


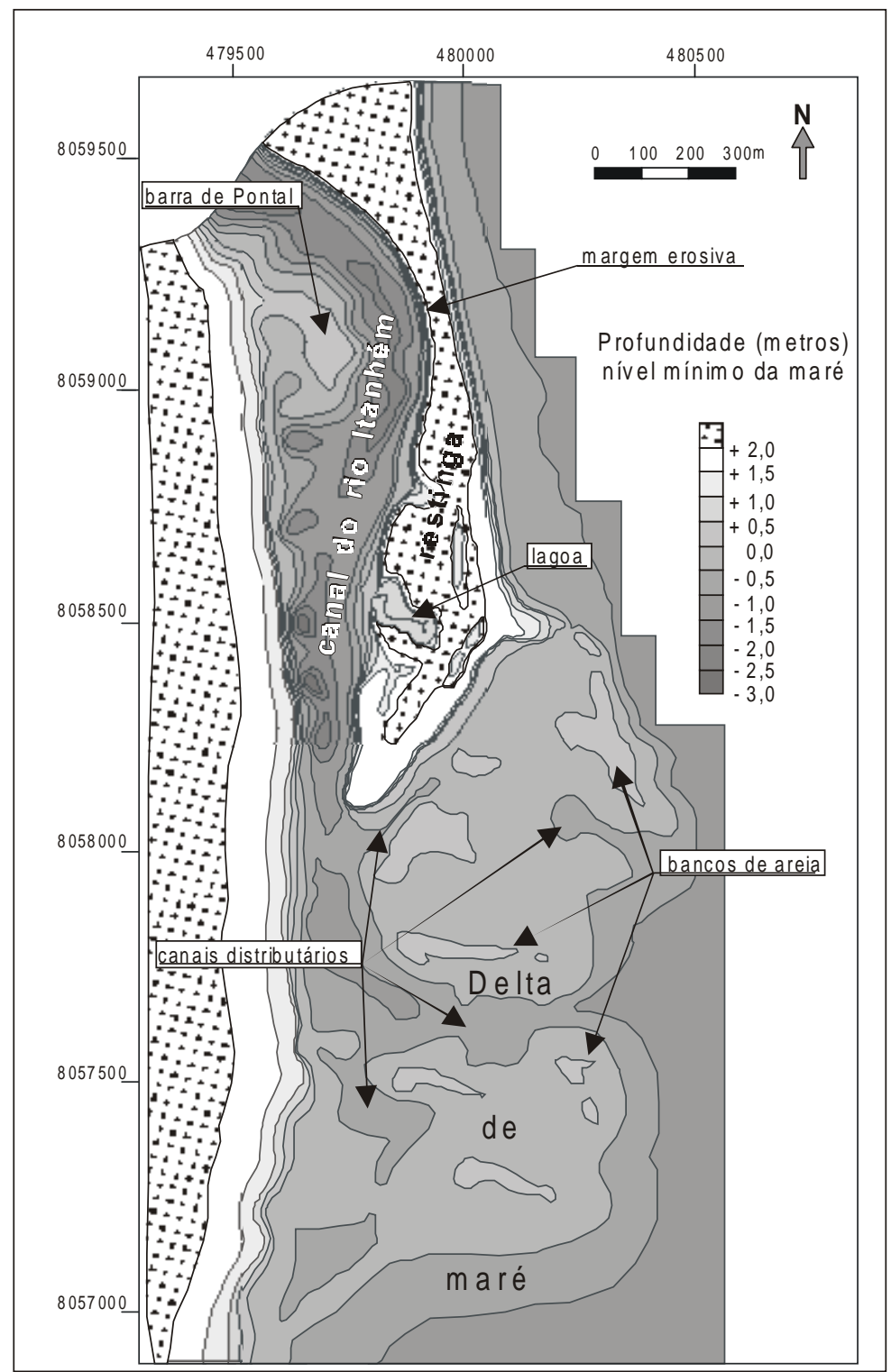

Figura 2: Mapa batimétrico da área estudada, envolvendo parte do estuário e delta de maré vazante do rio Itanhém. As áreas em branco são aquelas expostas na maré mais baixa.

Mata Atlântica na região (Dupont, 1998; Dupont et al., 1999). O problema de assoreamento tem transtornado a vida da população de Alcobaça, pois os barcos só conseguem chegar ao porto fluvial da cidade, entrando e saindo na barra do rio Itanhém, durante a maré cheia, pois facilmente os barcos encalham nos bancos de areia durante a maré baixa. Este problema ambiental tem afetado diretamente as duas principais atividades econômicas do município, a pesca e o turismo.

O conhecimento da dinâmica do transporte de sedimentos na área de estudo é de fundamental importância para qualquer obra de engenharia que venha a ser implementada para manter um curso navegável entre o rio e o mar. A área pesquisada sofre a influência de correntes de maré, do fluxo fluvial do rio Itanhém, e também do movimento oscilatório das ondas, revelando ambientes e processos extremamente dinâmicos.

\section{METODOLOGIA DE ESTUDO}

Os parâmetros granulométricos foram amplamente usados para identificar ambientes de deposição sedimentar (Folk \& Ward, 1957; Mason \& Folk, 1958; Friedman, 1961; Klovan, 1966), os processos sedimentares (Duane, 1964; Friedman 1967; Visher, 1969). Mais recentemente McLaren (1981) utilizou estes parâmetros para identificar os padrões de transporte de sedimento. McLaren (1981) e McLaren \& Bowles (1985) propuseram um método para deduzir as direções do transporte de sedimento a partir de mudanças espaciais em três parâmetros da granulometria: média, seleção e assimetria. A idéia básica do método é que as distribuições granulométricas nos ambientes sedimentares são afetados pela erosão, transporte e deposição seletivas. 


\section{MÉTODO DE MCLAREN}

McLaren (1981) relatou as mudanças nos parâmetros granulométricos a diferentes casos de transporte de sedimentos. Como os grãos leves possuem uma grande probabilidade de serem transportados, os depósitos residuais serão mais grossos, melhor selecionados, e mais positivamente assimétricos, do que o material original. O sedimento transportado será então mais fino do que o material da fonte. Quando o sedimento erodido é transportado e completamente depositado, o sedimento depositado será mais fino, melhor selecionado, e mais negativamente assimétrico.

Quando duas amostras são comparadas quanto a seus três parâmetros (média, seleção e assimetria), oito possíveis combinações existirão. De uma amostra para outra, a granulometria poderá ficar:
1) $\mathrm{FB}-$
5) FP-
2) $\mathrm{CB}+$
6) $\mathrm{CP}+$
3) $\mathrm{FB}+$
7) $\mathrm{FP}+$
4) $\mathrm{CB}$ -
8) $\mathrm{CP}-$

onde $\mathrm{F}=$ granulometria mais fina (Fine); $\mathrm{C}=$ granulometria mais grossa (Coarse); $\mathrm{B}=$ melhor selecionada (Better sorted); $\mathrm{P}=$ pior selecionada (Poorly sorted); - = mais negativamente assimétrica; $\mathrm{e}$ $+=$ mais positivamente assimétrica.

McLaren \& Bowles (1985) usando dados experimentais, concluíram que os depósitos sequenciais podem se tornar mais grossos, melhor selecionados, e mais positivamente assimétricos ( $\mathrm{CB}+$ ), ou mais finos, melhor selecionados, e mais negativamente assimétricos (FB-), na direção do transporte. Estas trajetórias são usadas para identificar os caminhos do transporte de sedimentos.

No Método de McLaren, as mudanças nas características granulométricas são examinadas ao longo de linhas de amostragem, onde cada amostra da linha é comparada com cada uma das demais amostras da linha. Dada uma linha com $\mathrm{n}$ amostras, existem

$$
\frac{n^{2}-n}{2}
$$

pares de amostras analisados em um sentido, e um número igual de pares no sentido oposto. É importante observar que nesta combinação de amostras, a primeira e a última amostra da linha constituem um par analisado. É obvio porém que quanto mais afastadas uma amostra da outra, menor será a dependência entre elas. Neste método supõe-se que a probabilidade de ocorrência de cada uma das associações é de 0,125 (equiprováveis, dentre as oito possibilidades). Entretanto, apenas as duas tendências que indicam o transporte de sedimentos (FBe CB+) são examinadas estatisticamente através de Teste de Hipótese, onde:

$\mathrm{H}_{0}$ : $\mathrm{p} £ 0,125$ (não existe direção preferencial);

$\mathrm{H}_{1}: \mathrm{p}>0,125$ (o transporte está ocorrendo em uma direção preferencial).

Para determinar se uma tendência ao longo de uma linha de amostras é significativa, McLaren \& Bowles (1985) utilizaram a estatística $Z$ como uma aproximação da binomial, ao nível de significância a\% (Z=1,645 para nível de significância de $95 \%$ e Z=2,33 para nível de significância de $99 \%$ ). Para que este teste seja válido, a linha amostral deve conter no mínimo 9 amostras. Desta forma,

$$
\begin{aligned}
& \mathrm{H}_{0} \text { é rejeitada se } \\
& \qquad \mathrm{Z}=\frac{\mathrm{X}-\mathrm{Np}}{\sqrt{(\mathrm{Npq})}}>\mathrm{Z} \alpha
\end{aligned}
$$

onde, $\mathrm{X}$ é o número de pares observado representando um caso particular de tendência em um dos dois sentidos opostos; $\mathrm{N}$ é o número total de pares possível em um sentido da linha, $\mathrm{p}=0,125$ e $\mathrm{q}=1$ $\mathrm{p}=0,875$.

A tendência (FB- ou $\mathrm{CB}+$ ) que indicar maior valor, em um determinado sentido da linha, ultrapassando o valor de $\mathrm{Z}$ tabelado, aceita-se como a direção do transporte.

\section{MÉTODO DE GAO \& COLLINS}

Gao \& Collins (1991) atestam que um tratamento bi-dimensional dos parâmetros granulométricos das amostras poderia produzir um resultado mais significativo, reduzindo o preconceito subentendido na escolha subjetivo das linhas de amostragem do Método de McLaren. Nessa aproximação bi-dimensional, cada amostra é comparada com as amostras vizinhas, através de seus parâmetros granulométricos: média, desvio padrão (coef. seleção) e assimetria. A vizinhança de cada amostra é determinada por uma distância característica $\left(\mathrm{D}_{\mathrm{cr}}\right)$, que é o intervalo espacial máximo. Sempre que uma tendência é identificada entre dois pontos, um vetor direcional adimensional é registrado nesta direção.

O primeiro passo é identificar os locais onde estão presentes os cursos direcionais granulométricos para cada tendência considerada (fig. 3). Os vetores direcionais em cada ponto são somados para produzir um único vetor resultante para cada tendência. Finalmente, uma técnica de suavização (filtragem) é aplicada para remover ou reduzir o ruído remanescente. Essa suavização consta de substituir, em cada ponto, o vetor resultante pela média dos vetores na vizinhança da amostra considerada, calculando a expressão:

$$
\mathrm{R}_{\text {av }}=\frac{1}{\mathrm{~K}+1}\left[\mathrm{R}(\mathrm{x}, \mathrm{y})+\sum_{1}^{\mathrm{k}} \mathrm{R}_{\mathrm{j}}\right]
$$

onde, $\mathrm{K}$ é o número de amostras vizinhas da amostra central $[\mathrm{R}(\mathrm{x}, \mathrm{y})]$ no interior do círculo com raio igual a $\mathrm{D}_{\text {cr }}$.

Os vetores formam assim, um padrão residual que representa o padrão mais provável do caminhamento do transporte de sedimento.

Gao et al. (1994) compararam o resultado do método em uma região onde o transporte de sedimento é conhecido e deduziram que: (1) os resultados indicados para a direção de transporte quando há um melhoramento da seleção possuem uma grande semelhança com o transporte conhecido; (2) já os 


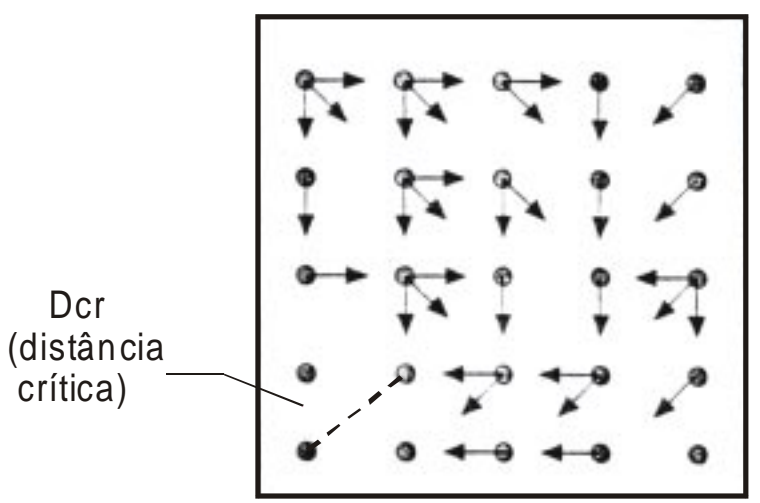

Figura 3: Exemplo de mapa mostrando as direções de transporte para una determinada associação de variações de parâmetros granulométricos (por ex. FB-).

resultados para os vetores granulométricos associados com um empobrecimento da seleção ao longo da direção do transporte de sedimento possuem pouco paralelismo com o transporte conhecido. Estes mesmos autores concluíram então que as tendências CB- e FB+ também podem ser indicativas do transporte de sedimentos. Entretanto, uma combinação baseada na soma vetorial entre as tendências FB- e $\mathrm{CB}+$ produz o melhor resultado.

\section{AMOSTRAGEM}

Inicialmente, foram mapeadas as margens do estuário do rio Itanhém, a linha de praia e os bancos de areia expostos na maré baixa. Em seguida foi possível planejar a amostragem que consistiu em uma malha regular de 80 × 80 metros (Fig. 4). As direções das linhas de amostragem foram escolhidas para que ficassem paralelas e perpendiculares à costa no delta de maré. As duas direções das linhas amostrais são, respectivamente, $60^{\circ}$ (linhas indicadas por números) e $150^{\circ}$ (linhas indicadas por letras) com relação ao norte magnético. As amostras foram denominadas com a letra e o número que indica a sua posição na interseção de duas linhas. As amostras coletam os $5 \mathrm{~cm}$ superiores do sedimento de fundo para que representem a granulometria resultando do transporte geral na área, desprezando variações momentâneas. Em água rasa, não teve dificuldades do marcar os pontos de amostragem com precisão. Em água mais profunda, foi usado um barco de pesca mas as correntes diversas dificultavam o posicionamento preciso do barco nos pontos de amostragem. Neste caso, conseguimos amostrar com precisão os pontos situados em água profunda depois de ter balizado todas as margens com estacas visíveis a distância e permitindo seguir um determinado rumo. $\mathrm{O}$ barco navegava seguindo um rumo definida e um

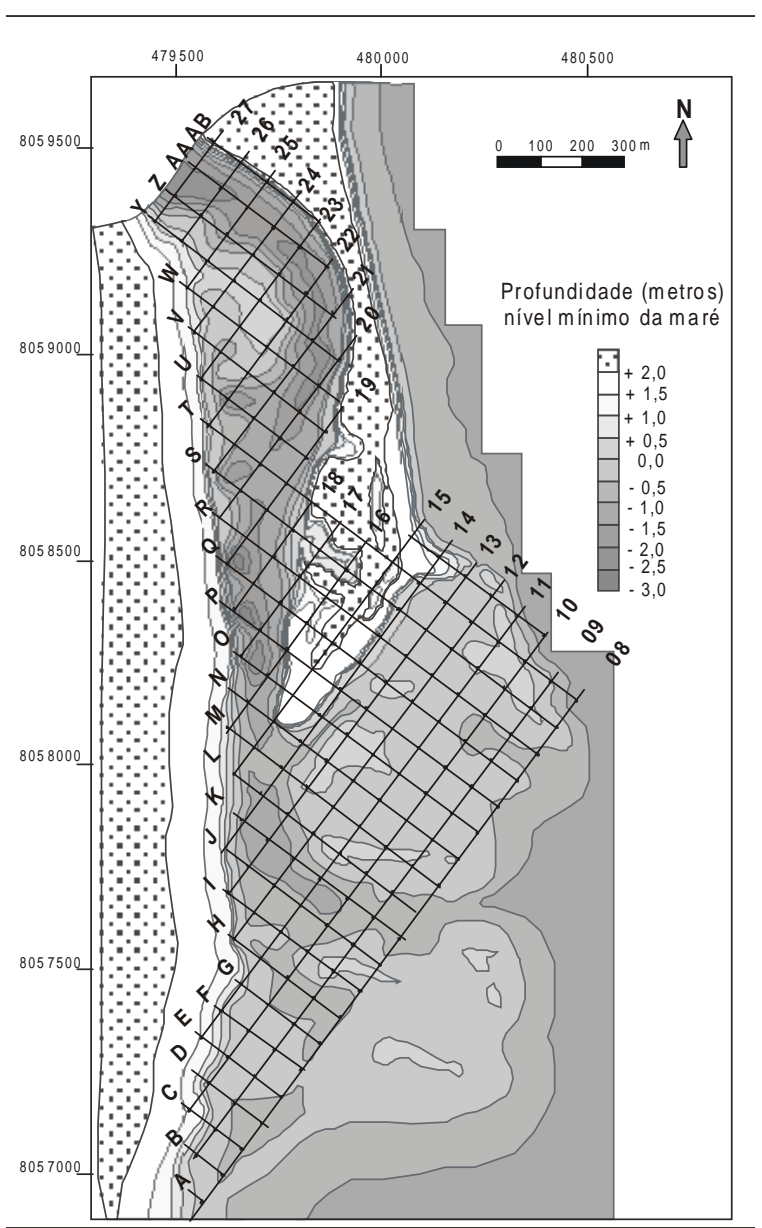

Figura 4: Malha de $80 \times 80$ metros utilizada para amostragem de sedimentos na desembocadura do rio Itanhém.

operador situado na margem visava uma direção perpendicular. O barco era avisado por rádio quando sua popa chegava no cruzamento das duas linhas e a amostragem era efetuada com um amostrador Rock Island. Repetindo a mesma manobra para cada ponto em água profunda, conseguimos um posicionamento bastante preciso das amostras. É evidente que para nossa malha de apenas $80 \mathrm{~m} \times 80 \mathrm{~m}$ a maior precisão possível do ponto de amostragem era necessária. $\mathrm{O}$ amostrador Rock-island consiste num cilindro de $10 \mathrm{~cm}$ de diâmetro e $30 \mathrm{~cm}$ de comprimento com uma haste de ferro fixada num anel soldado na parte central interna do fundo do amostrador. O amostrador amarrada a uma corda é lançado na água no local de amostragem. Este instrumento é especificado para retirar os primeiros $5 \mathrm{~cm}$ do sedimento de fundo. No momento da coleta de cada amostra eram colhidos dados sobre a direção da corrente de maré e a profundidade do local. Um total de 185 amostras de sedimento superficial, cada uma com aproximadamente $1 \mathrm{~kg}$, foi coletado na desembocadura do rio Itanhém. Entretanto, as amostras 112 e M15 foram descartadas por suspeita de serem depósitos antigos sendo erodidos, resultando em 183 amostras para 
análise. Estas amostras consistem em sua grande maioria de areia, mas também amostras de lama (silte e argila) e também mistura de areia e lama. Durante a amostragem, o nível da água foi monitorado em duas réguas de marés situadas no estuário e no delta de maré vazante. Isto possibilitou a correção das profundidades da lâmina d'água em cada ponto e assim construir o mapa batimétrico da área.

\section{PENEIRAMENTO}

Inicialmente, as amostras foram lavadas com o intuito de retirar o sal e a matéria orgânica presentes no sedimento, e depois secadas e quarteadas até atingirem um peso médio de 100 gramas. As frações grossas até o limite inferior do tamanho areia $(0,062 \mathrm{~mm})$ foram obtidas por peneiramento a seco em frações de $1 / 2 \mathrm{phi}$, e as partículas finas, tamanho silte e argila, foram analisadas através de difratometria de raio laser utilizando um aparelho Sympatec. O peneiramento a seco foi realizado utilizando uma mesa vibratória onde foram acoplados quatro jogos de 6 peneiras. Após o peneiramento, cada fração retida nas peneiras era pesada numa balança com precisão de $0,005 \mathrm{~g}$. Assim, foi possível calcular as percentagens em peso de cada intervalo de classe para produzir os histrogramas e curvas granulométricas.

\section{CÁLCULO DOS PARÂMETROS GRANULOMÉTRICOS}

Os parâmetros granulométricos média, desvio padrão (coeficiente de seleção) e assimetria foram calculados pelo método dos momentos. Os parâmetros estatísticos calculados pelo método dos momentos são afetados por cada ponto da distribuição de freqüência construída com intervalos de classe de $1 \frac{1}{2}$ phi e, portanto, representa melhor a distribuição granulométrica do que quando graficamente obtidos.

\section{APLICAÇÃO DO MÉTODO DE GAO \& COLLINS}

O Método de Gao \& Collins consiste em comparar os parâmetros granulométricos de cada ponto amostrado com os seus vizinhos. A Figura 5 apresenta os mapas das somas vetoriais para cada uma das associações de parâmetros indicativas do transporte de sedimentos (FB, $\mathrm{CB}+, \mathrm{FB}+$ e $\mathrm{CB}-$ ). Muitos pontos não mostram determinadas tendências (associações de parâmetros) em nenhuma direção, enquanto em outros pontos uma mesma tendência pode ser identificada em mais de uma direção. Quando duas ou mais direções ocorrem num mesmo ponto, a soma dos vetores unitários é realizada para produzir um único vetor resultante daquela tendência no local (Fig. 5). Desta forma, os vetores podem aumentar ou diminuir de magnitude, ou mesmo se anularem em cada ponto. A distância crítica de

$$
80 \sqrt{2}
$$

foi utilizada para que cada ponto fosse analisado com todos os seus vizinhos, no máximo oito. O resultado mostra um predomínio de ocorrência da tendência FBcom $32,5 \%$ das tendências. Na ordem de frequência esta é sucedida pela tendência $\mathrm{CB}+(24,3 \%)$, e em seguida as tendências FB+ $(23,5 \%)$ e CB- $(19,7 \%)$.

As tendências resultantes FB- (Fig. 5a) ocorrem bem distribuídas por toda a área, estando ausente apenas na região da lagoa e na margem direita do estuário em frente a ponta da restinga. As tendências resultantes $\mathrm{CB}+$ (Fig. 5b) são também bem distribuídas pela área amostrada, embora ocorra com menor frequiência que a tendência FB-. As tendências FB+ e CB- (Fig. 5c e d) possuem menor freqüência e estão mal distribuídas, ocorrendo regiões com muitos pontos sem nenhuma tendência identificada. As associações que indicam granulometria mais fina ( $\mathrm{FB}-\mathrm{e} \mathrm{FB}+$ ) predominam na direção do canal para as margens, enquanto que as associações indicando granulometria mais grossa $(\mathrm{CB}+$ e CB-) ocorrem predominantemente das margens em direção aos canais.

Em geral, as quatro associações mostram muitas características similares quanto à direção de transporte identificada. Por exemplo, todas as tendências indicam uma convergência do transporte em direção aos bancos de areia no delta.

As combinações de associações de parâmetros nada mais são do que a soma vetorial de duas ou mais associações em cada ponto, produzindo vetores resultantes entre as associações consideradas. Estas somas vetoriais são interessantes no sentido que espaços vazios existentes no mapa de uma determinada associação podem ser preenchidos por outra associação, produzindo um mapa vetorial mais completo. Outro fator importante é que quando mais de uma tendência de transporte é identificada em um ponto, o vetor resultante será maior se as tendências identificadas naquele ponto forem concordantes. Contrariamente, se as tendências identificadas em determinado ponto possuírem direções contrárias, o vetor resultante será diminuído ou mesmo anulado.

O resultado para a combinação das associações FBe $\mathrm{CB}+$ (Fig. 6) indica um transporte de sedimentos ao longo dos canais deltaicos convergindo em direção aos bancos de areia no delta de maré. Alguns vetores, na parte mais distal analisada, mostram um transporte em direção ao continente, contrário ao predominante em todo o delta, que é em direção ao mar. Dentro do estuário, as direções dos vetores ao longo do canal fluvial variam muito, predominando na direção do continente na parte superior do estuário e, em direção ao mar no restante do canal. A tendência de transporte na barra de pontal é da margem em direção ao canal evidenciando um crescimento lateral da barra.

O mapa vetorial da combinação de tendências FBe $\mathrm{CB}+$ (Fig. 6) foi suavizado através da operação de filtragem sugerida por Gao \& Collins (1991, 1992). Esta operação nada mais é do que o cálculo, para cada ponto, da média entre o vetor do próprio ponto e os vetores 


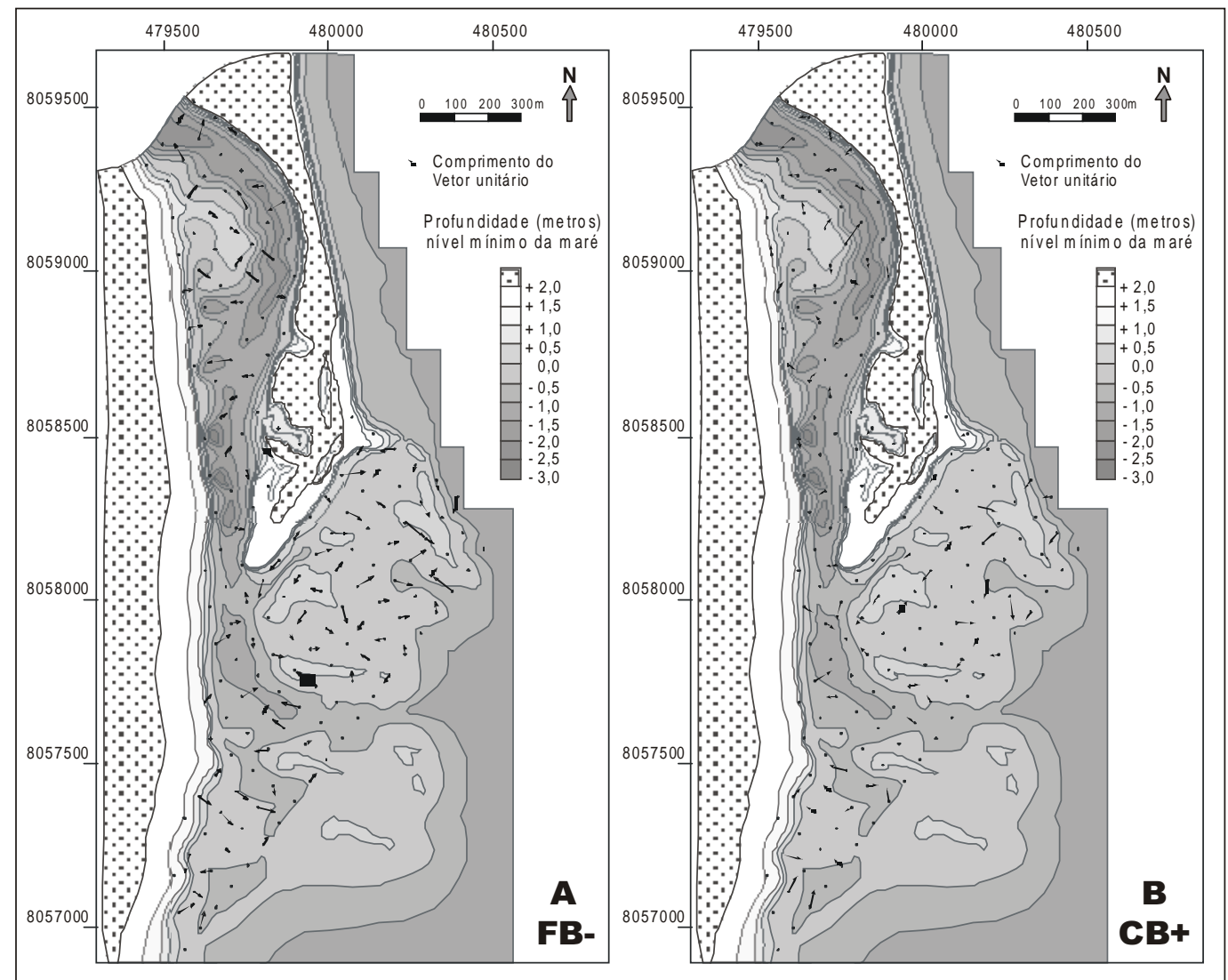

Figuras $5 a, 5 b$. Mapas mostrando os vetores resultantes para cada associação de parâmetros granulométricos. A) $F B-; B) C B+$.

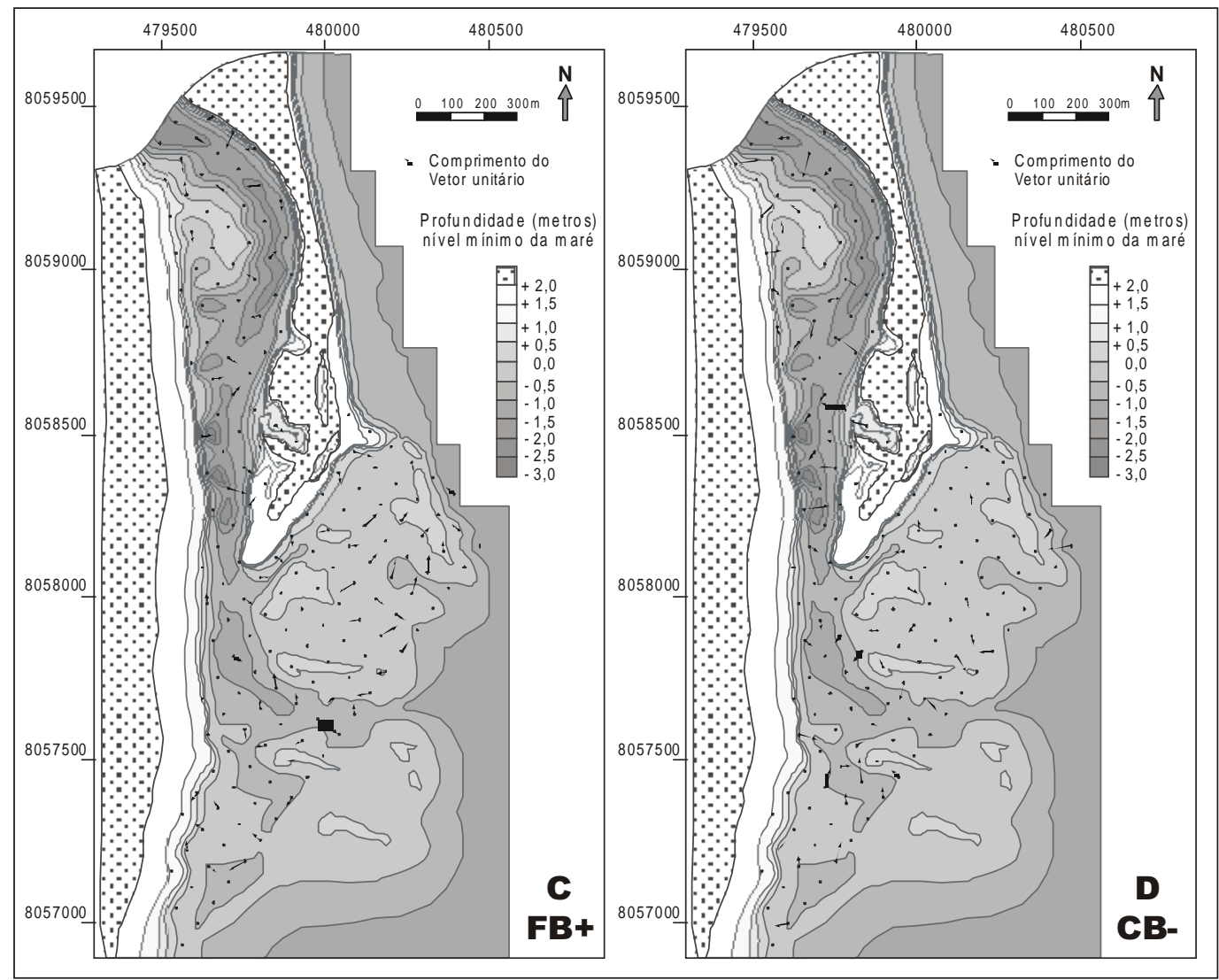

Figuras 5c, 5d: Mapas mostrando os vetores resultantes para cada associação de parâmetros granulométricos. C) $\mathrm{FB}+$; $\mathrm{D}) \mathrm{CB}$ - 


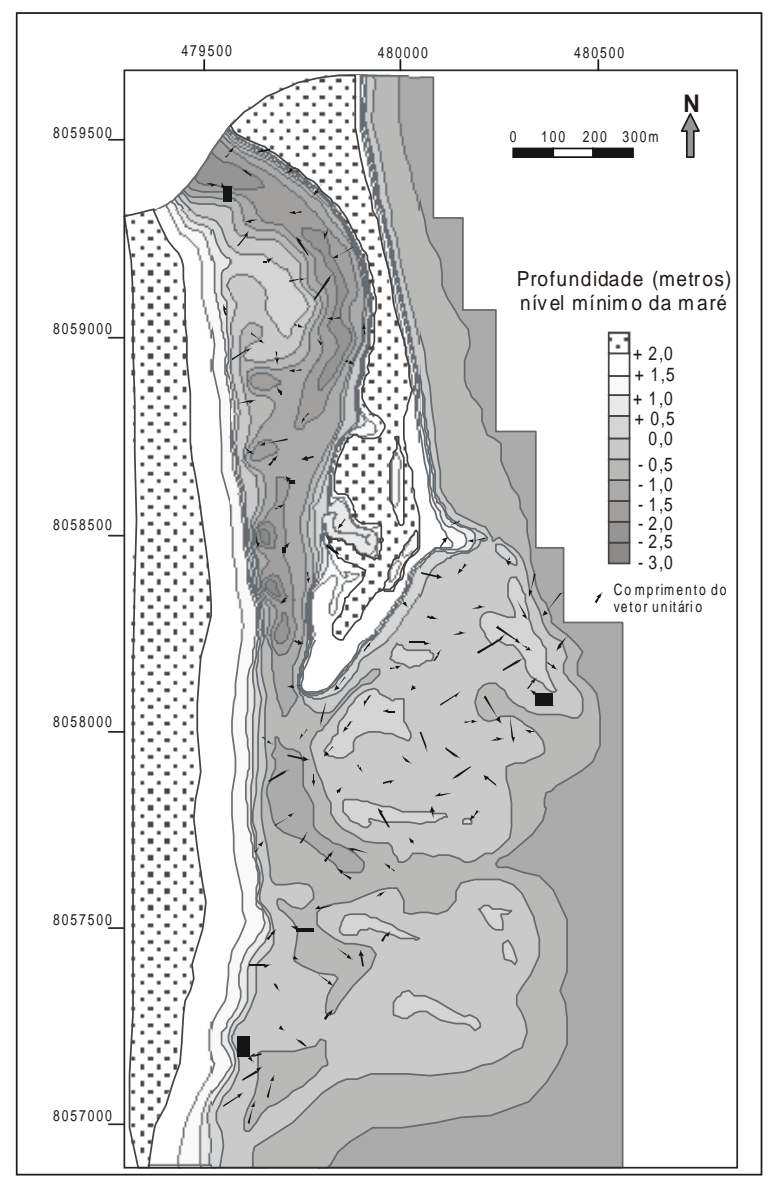

Figura 6: Mapa mostrando os vetores resultantes da combinação das associações $F B-e C B+$.

vizinhos. Desta forma, o resultado da filtragem define melhor um padrão para grupos de amostras vizinhas. Ela produz também vetores para locais antes sem tendência definida, pela média apenas dos vizinhos. Os mapas suavizados são o produto final do Método de Gao \& Collins para o transporte de sedimentos na área estudada (Fig. 7).

O mapa suavizado para a combinação entre FB- e $\mathrm{CB}+$ (Fig. 7) mostra um padrão de convergência dos vetores para a maior parte dos bancos de areia no delta de maré e também no sentido da lagoa na restinga. De acordo com este mapa, o transporte de sedimentos ocorre ao longo do canal fluvial e canal principal do delta em direção ao mar. $\mathrm{Na}$ barra de pontal, os vetores indicam transporte lateral ao longo da barra, com aporte de sedimentos predominantemente a partir da jusante do estuário. $\mathrm{Na}$ parte sul do delta, ocorre uma região de divergência de vetores, assim como entre os bancos de areia na parte norte do delta.

\section{KRIGAGEM VETORIAL}

Uma forma de obter mapas resultando em um número de vetores maior do que o número de pontos amostrados é realizando uma interpolação dos vetores, inicialmente produzidos pelo Método de Gao \& Collins (Bodevan,

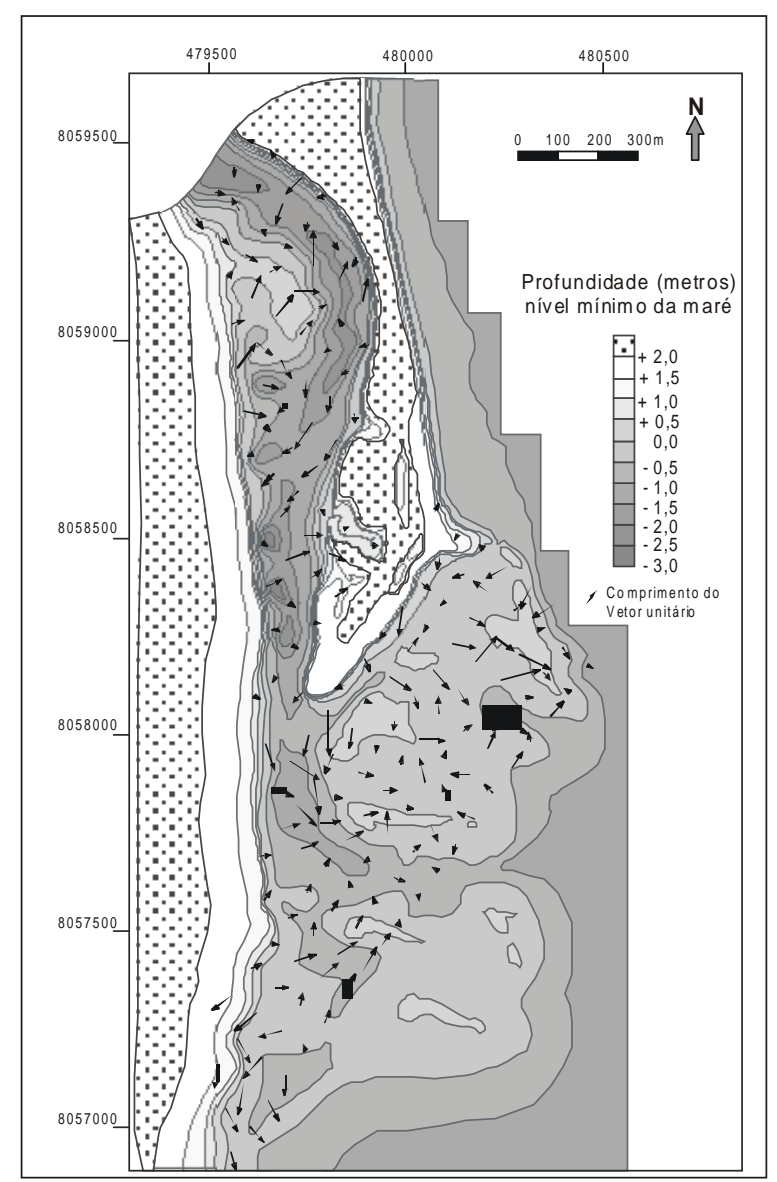

Figura 7. Mapa mostrando o resultado para a suavização dos vetores da Fig. 6.

2000). O procedimento de filtragem sugerido por Gao \& Collins não é utilizado neste método e é substituído pela krigagem dos vetores. A krigagem, entretanto, interpola apenas uma variável, neste caso, a direção dos vetores, não considerando a magnitude dos mesmos. A Figura 8 apresenta o mapa da combinação FB- e CB+ com os vetores direcionalmente krigados para uma malha de 40x40 metros.

O mapa resultante deste método apresenta uma estrutura direcional dos vetores muito bem organizada fruto da operação de krigagem. Esta interpolação conserva o mesmo vetor identificado em cada ponto e produz vetores intermediários médios analisando apenas a vizinhaça do ponto. O resultado prova indicar as principais trajetórias do transporte de sedimentos com uma interpretação mais rápida e clara.

O transporte de sedimentos, indicado pelo Método de krigagem direcional, é feito dominantemente em direção ao mar. Este padrão muda na barra de pontal e em frente à lagoa da restinga, onde os vetores indicam transporte lateralmente ao canal. Os vetores indicando o transporte de sedimentos indicam que a restinga sofre erosão em sua margem oposta à barra de pontal e acreção no restante de sua margem. No delta de maré, ocorre uma convergência dos vetores na direção dos principais bancos de areia. As zonas de divergência dos vetores coincidem 


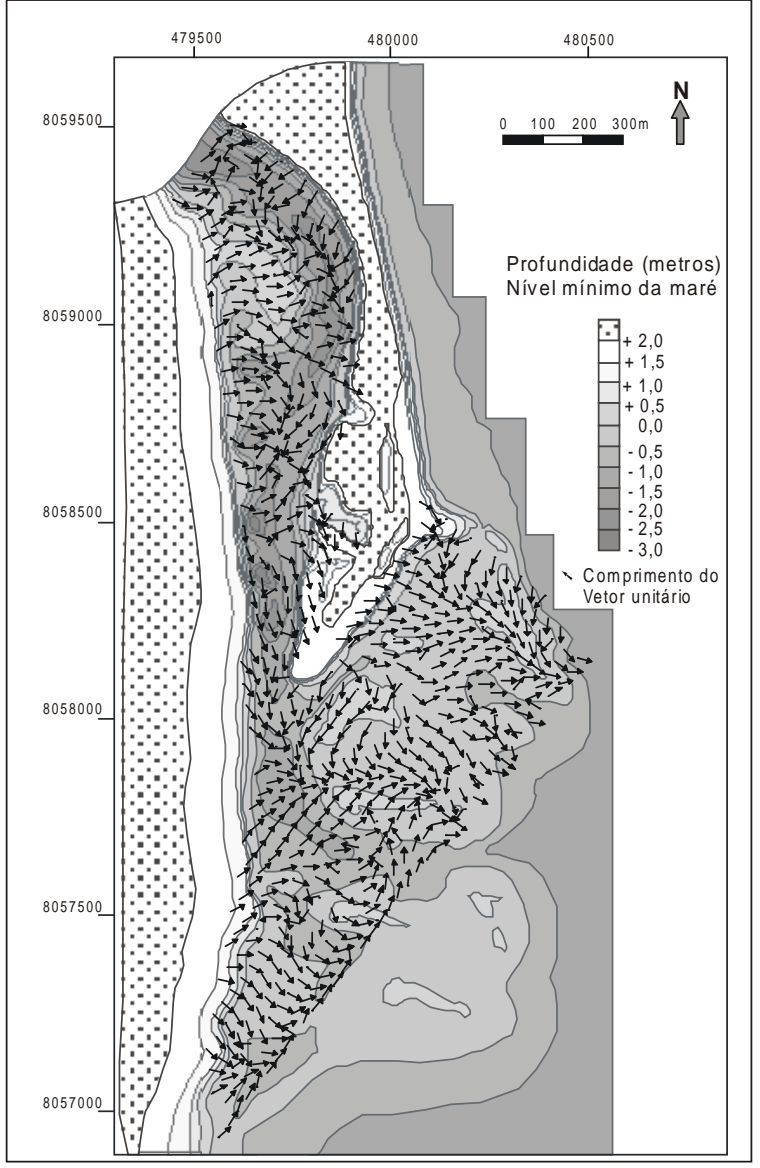

Figura 8: Mapa mostrando o resultado para a krigagem das direções dos vetores da Fig. 6.

com os canais distributários mais profundos.

Comentários sobre os parâmetros granulométricos como indicadores do transporte sedimentar residual na zona litorânea

Mesmo considerando os resultados aparentemente positivos conseguidos nesta pesquisa, é importante discutir em quais condições esta metodologia introduzida por McLaren como "Sediment Trend Analysis®", posteriormente modificada por Gao e Collins e novamente modificada, neste trabalho, pelo uso de krigagem direcional pode representar uma vantagem sobre o uso da sedimentologia tradicional através da observação das formas de leito e da experimentação com traçadores. Também, é importante refletir sobre quais pesquisas complementares poderiam ser oportunas para reforçar o embasamento teórico, experimental e de observação desta técnica e melhorar o tratamento estatístico dos dados granulométricos.

Esta nova metodologia objetiva caracterizar o padrão do transporte sedimentar residual correspondendo a grandes intervalos de tempo, em rios, estuários e zonas litorâneas, e caracterizar, se possível, áreas de transporte, de erosão e de acreção. Assim, pretende resolver de maneira nova a pesquisa que seria tradicionalmente abordada pelo estudo das várias escalas de formas de leito direcionais. A premissa defendida por McLaren e Gao \&
Collins é que a amostragem em malha regular dos centímetros superiores do leito sedimentar e o estudo estatístico dos seus parâmetros granulométricos pode fornecer mais facilmente uma interpretação do padrão da dinâmica sedimentar geral que o estudo e a interpretação das várias escalas de estruturas sedimentares direcionais eventualmente combinadas com o uso de traçadores. Especialmente em estuários de grande porte, com geomorfologia complexa, lâmina d'água importante e água geralmente turva, uma amostragem do sedimento de fundo em malha regular pode ser mais facilmente executado que uma pesquisa detalhada através das estruturas sedimentares. Na prática grandes projetos de dragagem precisam ser executados periodicamente em estuários de vários quilômetros de largura onde transitam navios oceânicos. O planejamento dos canais de navegação a serem dragados e das áreas onde o material dragado poderá ser estocado sem risco de voltar rapidamente a assorear os canais são assuntos importantes para limitar ao máximo o custo destas dragagens periódicas. Nestes casos, especialmente, a metodologia de "Sediment Trend Analysis®" é bastante requisitada por companhias portuárias e executada pela empresa GeoSea do Dr. McLaren.

Em áreas restritas como o estuário do rio Itanhém, mesmo que uma interpretação razoável da dinâmica sedimentar pudesse ser conseguida com métodos tradicionais, os métodos de McLaren ou de Gao \& Collins podem trazer informações interessantes desde que a malha de amostragem seja adaptada ao tamanho da área e das feições sedimentares que modelam a morfologia do fundo. Nos lugares mais estreitos do estuário, apenas três amostras de sedimento coletados na transversal são insuficientes para permitir uma boa análise do padrão de transporte pelo método bidimensional, já que as duas amostras das bordas não serão corretamente suavizadas. No delta de maré vazante, bancos de areia com apenas trinta metros de largura entre canais com tamanho um pouco superior poderão dificilmente ser detectados com uma malha de amostragem de $80 \mathrm{~m}$ x 80m. Provavelmente uma malha de $40 \mathrm{~m} \times 40 \mathrm{~m}$ teria sido ideal ou $60 \mathrm{~m} \times 60 \mathrm{~m}$ ainda bastante satisfatória. O problema é que uma eqüidistância de $40 \mathrm{~m}$ resulta em quatro vezes mais amostras a serem coletadas e tratadas para serem calculados os parâmetros granulométricos. Além disso o posicionamento preciso em áreas onde atuam correntes diversas é bastante difícil como foi explicado no parágrafo sobre amostragem.

Entretanto, os métodos analisados neste trabalho apresentam ainda questionamentos que podem induzir a um resultado incorreto. Em primeiro lugar não existe ainda um bom acervo de dados apoiando a base teórica do método e em segundo lugar o tratamento estatístico apresenta ainda alguma deficiências.

\section{ACERVO DE DADOS COMPROVANDO A BASE TEÓRICA DO MÉTODO}

A teoria formulada por McLaren (1981) e McLaren \& Bowles (1985) com relação às principais mudanças 
na granulometria na direção do transporte representadas pelos padrões FB- e $\mathrm{CB}+$ parece condizer com a verdade na maior parte dos casos. Entretanto, falta ainda entender exatamente como muda a granulometria na direção de transporte nos diversos processos sedimentares existentes. Em outras palavras, qual a relação entre cada associação de parâmetros e os diversos tipos de transporte de sedimentos. Esta relação fornece a base teórica para esta metodologia e a resposta para isto permanece ainda obscura. Gao e Collins que consideram quatro associações de parâmetros significativos de direção de transporte (FB, $\mathrm{CB}+, \mathrm{FB}+, \mathrm{CB}-)$ baseiam-se principalmente sobre uma lista de publicações relativamente antigas. A sugestão é que se desenvolva uma pesquisa realizando experimentos físicos com o intuito de compreender a quais processos sedimentares cada associação de parâmetros está relacionada.

\section{TRATAMENTO ESTATÍSTICO ADOTADO POR CADA MÉTODO}

Pode ser questionada a escolha subjetiva das linhas amostrais para analisar o transporte de sedimentos no método de McLaren. O teste estatístico usado neste Método é mais significativo quanto maior o número de amostras envolvidas. Porém, quanto mais longe uma amostra encontra-se da outra, menor é a sua dependência espacial e, portanto, não deveriam ser comparadas. Outro problema detectado é que o teste utilizado por McLaren produz um resultado baseado apenas na freqüência das associações com relação ao número total de pares de amostras analisados em cada linha. A conclusão é que o Teste de Hipótese adotado por McLaren pode ser considerado significativo também em muitas direções não coincidentes com a direção de transporte. Desta forma, o método é subjetivo podendo apresentar resultados diferentes a partir da escolha de outras linhas pelo investigador.

O método desenvolvido por Gao \& Collins fornece um resultado mais objetivo pois este analisa cada ponto apenas com seus vizinhos. Este método ainda produz uma magnitude para os vetores indicativos do transporte de sedimentos que está relacionada a uma maior ou menor tendência do transporte estar ocorrendo em uma direção. Um problema apresentado pelo Método de Gao \& Collins é o efeito de borda. As amostras localizadas nos limites da malha de amostragem possuem uma vizinhança menor e consequentemente produzem uma análise viciada. Por este motivo, a maior parte das amostras de borda indicam transporte para o interior da região amostrada.

O Método de Krigagem Vectorial possui limitações no sentido que este interpola apenas a direção dos vetores desprezando as seus módulos. A solução para este problema seria aplicar a técnica de Krigagem Multivariada, conhecida como Co-krigagem, onde interpola-se duas ou mais variáveis. Este problema deverá ser resolvido no futuro próximo. Com relação às bordas, todos os seus pontos possuem, também, um erro maior de interpolação na krigagem vetorial.
Pode-se concluir contudo que a aplicação de cada um dos métodos contribui para a análise geral da direção do transporte de sedimentos. Cada método possui suas características que se completam e ajudam a compreender a dinâmica sedimentar local.

\section{REFERÊNCIAS BIBLIOGRÁFICAS}

Asselman, N. E. M. 1996. Grain size characteristics used to identify sediment transport pathways on fine grained aggrading floodplains. Report ICG 96/5, Utrecht University, Holanda, 38p.

Bodevan, E. C. 2000. Análise espacial de dados vetoriais através da krigagem direcional. Aplicação à dinâmica de transporte de sedimentos. Depto de Estatística, Universidade Federal de Minas Gerais, Belo Horizonte. Dissertação de Mestrado, 98p.

Davis Jr. , R. A. 1983. Depositional Systems: A Genetic Approach to Sedimentary Geology. New Jersey: Prentice-Hall, 669p.

Duane, D. B. 1964. Significance of skewness in recent sediments, Western Pamlico Sound, North Carolina. Journal of sedimentary petrology, 34:864-874.

Dupont, H. 1998. Delta sedimentation causing erosion in south Bahia, Brazil. Journal of Coastal Research, SI.26:256-260.

Dupont, H., Ribeiro, L. V. \& Temba, P. C. 1999. Impacto da atividade humana recente e atual na região de Alcobaça, extremo sul da Bahia. In: Congresso da ABEQUA, 7, Porto Seguro. arquivo: VIIABEQUA_HEO001.pdf. (CD-ROM).

Dupont, H., Ribeiro, L. V., Lúcio, P. S., Bodevan, E. C. 2000. Sediment transport trend at Itanhém's river estuary, Alcobaça, South Bahia, Brazil. Proceedings of the Brazilian Sandy Beaches Symposium. Univali, Itajaí. 107-109.

Folk, R. L. \& Ward, W. C. 1957. Brazos River bar: a study in the significance of grain size parameters. Journal of Sedimentary Petrology, 27:3-26.

Friedman, G. M. 1961.Distinction between dune, beach and river sands from textural characteristics. Journal of Sedimentary Petrology, 31:514-529.

Friedman, G. M. 1967. Dynamic processes and statistical parameters compared for size frequency distribution of beach and river sands. Journal of Sedimentary Petrology, 37:327-354.

Gao, S. \& Collins, M. B. 1991. A critique of the "McLaren method" for defining sediment transport paths-discussion. Journal of Sedimentary Petrology, 61,1:143-146.

Gao, S. \& Collins, M. B. 1992. Net sediment transport patterns inferred from grain-size trends, based upon definition of "transport vectors". Sedimentary Geology, 81:47-60.

Gao, S., Collins, M. B., Lanckneus, J., De Moor, G. \& Van Lancker, V. 1994. Grain size trends associated with net sediment transport patterns: An example from the Belgian continental shelf. Marine Geology, 121:171-185.

Klovan, J. E. 1966. The use of factor analysis in determining depositional environments from grain-size distributions. Journal Sedimentary Petrology, 36,1:115-125.

Le Roux, J. P. 1994a. A spreadsheet template for determining sediment transport vectors from grain-size parameters. Computers \& Geosciences, 20,3:433-440.

Le Roux, J. P. 1994b. An alternative approach to the identification of net sediment transport paths based on grain-size trends. Sedimentary Geology, 94:97-107.

Mason, C. C., Folk, R. L. 1958. Differentiation of beach, dune, and aeolian flat environments by size analysis, Mustang Island, Texas. Journal of sedimentary petrology, 28,2:211-226.

McLaren, P. 1981. An interpretation of trends in grain size measures. Journal of Sedimentary Petrology, 51,2:611-624.

McLaren, P. \& BOWLES, D. 1985. The effects of sediment transport on grain-size distributions. Journal of Sedimentary Petrology, $55,4: 457-470$.

Ribeiro, L. V. 2000. Dinâmica do transporte de sedimentos pela análise da variação espacial na granulometria. Instituto de Geociências, Universidade Federal de Minas Gerais, Belo Horizonte. Dissertação de Mestrado em Geologia Aplicada, 113p.

Visher, G. S. 1969. Grain size distribution and depositional processes. Journal of Sedimentary Petrology, 39,3:1074-1106. 